\title{
Increasing the efficiency of diesel engines operation by changing the process of fuel injection into the combustion chamber
}

\author{
Igor Ivanov ${ }^{1, *}$ \\ ${ }^{1}$ Don State Technical University, 1, Gagarin sq., 344003, Rostov-on-Don, Russia
}

\begin{abstract}
This paper proposes the author's method of developing a constructive solution for supplying fuel to the combustion chamber to reduce fuel consumption in operation on the basis of TIPS (theory of inventive problem solving).
\end{abstract}

\section{Introduction}

Currently, diesel engines are widely used in various fields of agricultural industry and in various types of transport. Moreover, despite the specific features of the work process in different areas, there are common problems [1]. In this case, the mode operation process is often carried out [2]. In this case, the extreme modes are idle and nominal engine operation modes. Practically, while developing a new diesel engine, the great attention was focused on developing a structure that would provide effective rate at nominal conditions.

But in the process of operation it turned out that these engines have significant fuel consumption in operation due to the unsatisfactory process of operation at idle and low loads modes. Meanwhile, not only the fuel consumption increased, but the duration term of the engine also decreased, due to the dilution of the oil when unburned fuel got into the crankcase. To increase the engine efficiency at idle and low loads modes, the following things should be done: changing the air supply [3,4], changing the fuel composition [5], introducing an exhaust gas recirculation system [6-12].

Although the proposed methods improve the workflow in this mode, they make the structure more complicated and require using fuel of higher quality.

\section{Urgency}

On the basis of numerous studies of the diesel engine operation process in different operating modes, it was found that the requirements for the fuel injection process will be different in this case. This is due to the fact that under the nominal mode, it is necessary to ensure intensive mixing of fuel with air oxygen in the volume of the combustion chamber due to the supply of fuel to all parts of the combustion chamber and intense vortexing. At idle mode, it becomes difficult for the fuel to self-ignite when a small amount of fuel is supplied to a large volume of the combustion chamber at a relatively low temperature. At the same time, the

*Corresponding author igoriv740@yandex.ru 
vortexing of the air worsens the self-ignition process. The result is lower fuel consumption in operation and a shorter engine duration term. Therefore, it is necessary to find a compromise solution for low fuel consumption in operation.

\section{Problem formulation}

Since there are different requirements of the fuel supply process at idle and nominal load modes, it is necessary to find a fundamentally new solution to develop the structure of a device for spraying fuel in order to ensure minimum fuel consumption in operation.

\section{The theoretical part}

1. Combustion process analysis.

Since it is very difficult to create a model of the fuel self-ignition process and the combustion front spreading for a diesel engine, the author investigated the combustion of diesel fuel in a rotating air stream with a vortex velocity close to the idle mode of a D100 diesel engine.

The burning flame gas analysis showed that only at a low vortex velocity, light components such as $\mathrm{CO}, \mathrm{H} 2$ and $\mathrm{CH} 4$ in small amounts are formed at the combustion limit. Therefore, the results of combustion were evaluated in terms of the content of $\mathrm{CO} 2$ and $\mathrm{O} 2$. At the same time, the intensity of combustion was assessed by the indicator - Q, which was determined by the ratio of $\% \mathrm{CO} 2$ to $\mathrm{CO} 2-\max$. For CO2-max $11.9 \%$ is taken - the maximum value of $\mathrm{CO} 2$ obtained during this investigation.

The results of the dependence of $Q$ on the distance of the measuring point from the center of the pipe, where the combustion took place, at a flow rate of $8.3 \mathrm{~m} / \mathrm{s}$ is shown in Fig. 1 . For other lower flow rates, the dependences have a similar character with a decrease in the combustion zone of the outer layer. Thus, the tests discovered that the flame is concentrated in the center of the rotating flow and its area increased towards the outer surface with increasing rotation speed.

Based on the test data, it was concluded that at idle mode on the purpose of better selfignition, it is advisable to supply fuel in the form of a concentrated jet in the direction of the rotating air flow center.

To prove this hypothesis, experimental injector nozzles were made and bench tests were carried out. It was understood that while installing injectors with one hole instead of three on one side of the diesel engine, fuel consumption decreased, but at the same time it increased in the nominal mode. Therefore, the task how to reduce fuel consumption at idle mode, and not to increase at the nominal mode arose. $14]$.

2. Using elements of TIPS (theory of inventive problem solving) to solve a problem [13,

To solve it, we will compose technical contradictions (TC):

TC-1. To increase the efficiency of the combustion process in a diesel engine at the nominal mode, fuel must be injected throughout the entire volume of the combustion chamber, but at the same time, at idle speed, starting mode and low loads, the working process deteriorates and fuel consumption increases. 


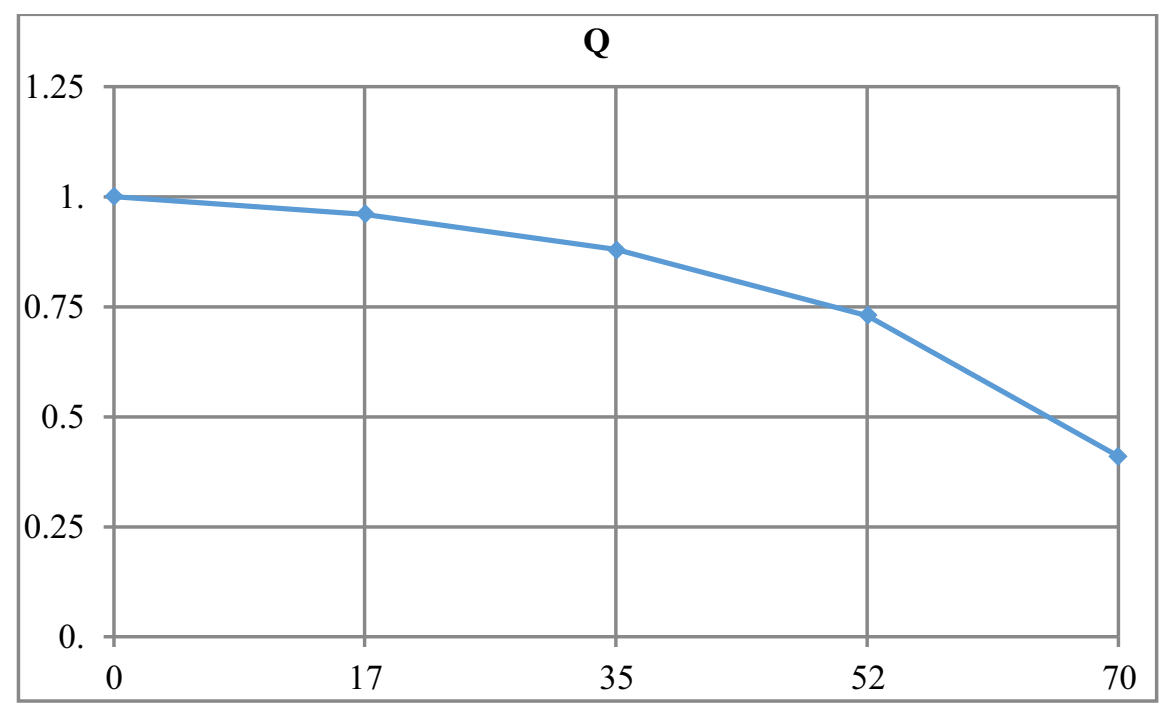

Fig. 1. Dependence of the combustion intensity $\mathrm{Q}$ on the distance to the center of the flame $(\mathrm{mm})$.

TC-2 In order to increase the efficiency of the combustion process in the start-up mode at idle speed and at low loads, the fuel must be supplied in the direction to the center of the rotating air flow in the form of a concentrated jet, but this deteriorates the working process at the nominal mode.

TC-2 will be taken as a basis, as it corresponds to the determined goal.

To eliminate this contradiction, it was proposed that instead of one concentrated jet, fuel should be supplied by several closely located parallel jets, which will provide a high range due to a reduction in pressure losses, with one direction of nozzle holes and a well, as well as due to the formation of a vacuum inside parallel jets, which have closely located axes. At the same time, injection in the form of several jets provides a fine atomization, which provides an improvement in the combustion process at the nominal mode.

The design of the nozzle tip for the 10D100 diesel engine developed by the author is shown in Figure 2. [15].

\section{Practical results}

To check this idea, experimental nozzle tips were made and comparative bench tests were carried out. Tests on a 10D100 diesel engine were carried out with three variants of nozzle tips: standard, experimental single-hole with the diameter of $0.8 \mathrm{~mm}$ and the direction of the axis of the nozzle hole parallel to the axis of the well at the angle of $80^{\circ}$ to the axis of the cylinder and experimental three-hole nozzles with a diameter the $0.5 \mathrm{~mm}$ with the axes of the nozzle holes located parallel to the axis of the well and to each other at the angle of $80^{\circ}$ to the axis of the cylinder.

At the same time, standard and experimental injectors were changed on all cylinders of the right side of the diesel engine, and on the left side there were standard injectors (one right row of injectors operates at idle mode, and both rows operate at loads). All injectors were preliminarily checked and adjusted to the same pressure of 21.0 MPa. During the tests, the fuel advance angle was standard $10^{\circ}$ to the top dead point of the lower piston.

The test results at the nominal mode are shown in Table 1. 


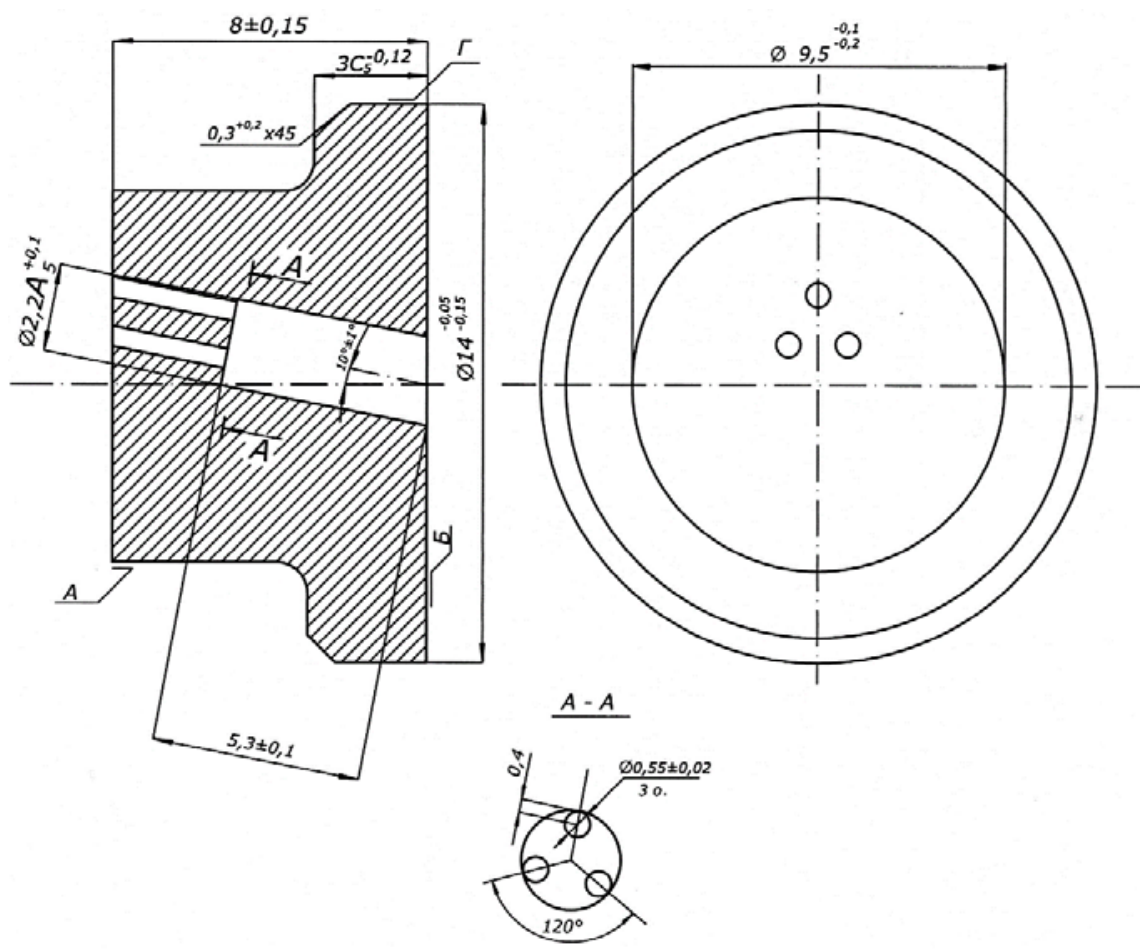

Fig. 2. Design of a nozzle tip with channels parallel to the spray holes.

Table 1. Test results at nominal mode.

\begin{tabular}{|c|l|c|c|c|c|}
\hline No & \multicolumn{1}{|c|}{ Atomizer type } & $\begin{array}{c}\mathbf{N e .}_{\mathbf{k}} \\
\mathbf{k W t}\end{array}$ & $\begin{array}{c}\mathbf{G} \mathbf{G e} \\
\mathbf{g} / \mathbf{k W t * h}\end{array}$ & $\begin{array}{c}\mathbf{T}_{\mathbf{B}} \mathbf{} \\
\mathbf{}^{\mathbf{C}}\end{array}$ & $\begin{array}{c}\mathbf{P}_{\mathbf{z}} \\
\mathbf{M P a}\end{array}$ \\
\hline 1 & $\begin{array}{l}\text { Standard atomisers on the right and left } \\
\text { side }\end{array}$ & 2083 & 250.1 & 353.6 & 9.9 \\
\hline 2 & $\begin{array}{l}\text { Tested ones: single-hole on the right side } \\
\text { of the diesel. and on the left side are } \\
\text { standard }\end{array}$ & 1988 & 253.1 & 361.9 & 10.3 \\
\hline 3 & $\begin{array}{l}\text { Tested ones- three-hole ones with a } \\
\text { parallel direction of fuel jets on the right } \\
\text { side of the diesel engine. and standard } \\
\text { ones on the left side. }\end{array}$ & 2079 & 250.9 & 357.5 & 10 \\
\hline
\end{tabular}

The results of the tests at idle mode are shown in Figure 3.

At the same time, at the test station, the equilibrium temperature mode can be set only for the nominal mode. At idle mode, it is difficult to establish an equilibrium temperature mode, and the fuel consumption of a 10D100 diesel engine at this mode significantly depends on the temperature of oil and water. Therefore, fuel consumption was measured at different temperatures and the dependence of fuel consumption on temperatures for standard and experimental injectors was determined.

Moreover, as the consumption of $1 \mathrm{~kg}$ of fuel lasts for a considerable period of time, for the accuracy of the calculation the temperature was determined before the start of taking readings and after finishing, and the average value was taken into account. For an objective 
assessment of the results at varying oil temperatures, the experimental data were processed by the nominal regression method. All injectors were preliminarily checked and adjusted to the same pressure of $21.0 \mathrm{MPa}$. The tests were carried out at a standard fuel feed advance angle of $10^{\circ}$ to the top dead center of the lower piston.

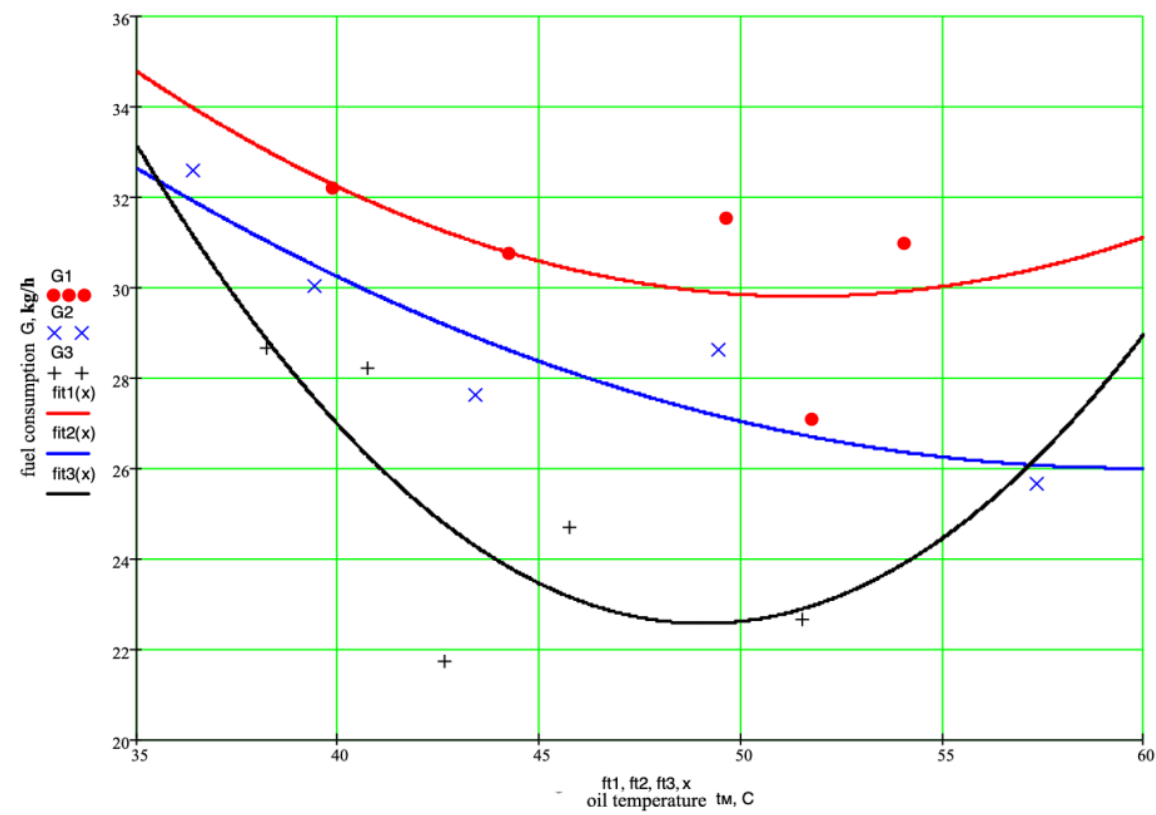

Fig. 3. Dependence of fuel consumption $(G)$ on oil temperature at idle mode of a 10D 100 diesel engine when using different injectors: G1 - experimental data when using a standard $(3 \times 0.56)$ injector; G2 - experimental data when using an experimental single-hole (1x0.9) nozzle; G3 experimental data when using an experimental three-hole $(3 \times 0.55)$ nozzle with a parallel direction of the jets; fit (1), fit (2), fit (3) - functions G1, G2, G3, approximated by the method of polynomial regression, respectively.

The tests have shown that the fuel injection in the form off three parallel jets made it possible to improve the working process at nominal conditions in comparison with singlehole nozzles, making it almost equal to serial three-hole nozzles (the difference in fuel consumption of $0.3 \%$ is close to the measurement error). At the same time, fuel consumption at idle mode has sharply decreased in comparison with serial ones from 14.9 to $27.4 \%$, and in comparison with single-hole from 10.2 to $16.2 \%$, depending on the temperature mode.

\section{Conclusion}

1. The fuel injection developed by the author in the form of several closely located parallel jets provides the flame range and high dispersion of the fuel atomization.

2. The proposed technology allows to reduce fuel consumption in operation and can be recommended for engines that, according to operating conditions, must operate at different modes.

\section{References}

1. V. Kvashin, V. Sherbakova, S. Zakharov, Bulletin of Omsk State Agrarian University 2(30), 109-115 (2018) 
2. I. Ivanov, G. Persiyanova, Materials of the 7th International Scientific and Practical Conference, within the 17th International Agroindustrial Exhibition "Interagromash2014", 396-397 (2014)

3. Vedruchenko, V. Krainov, E. Lazarev, P. Litvinov, Omsk Scientific Bulletin. Ser. Devices, machines and technologies 6(150), 68-72 (2016)

4. E. Lazarev, A. Pomaz, A. Salov, Bulletin of the South Ural State University. Mechanical Engineering Series, 132-136 (2013)

5. A. Ukhanov, D. Ukhanov, I. Adgamov, Journal Niva of the Volga region 1(34), 66-71 (2015)

6. I. Ivanov, E3S Web of Conferences 210, $08013 \quad$ (2020) DOI https://doi.org/10.1051/e3sconf/202021008013

7. United States Patent no. 10,634,101, Application No. 15/632,975, http://patft.uspto.gov/netacgi/nph-

Parser?Sect $1=$ PTO2\&Sect $2=$ HITOFF $\& \mathrm{p}=1 \& \mathrm{u}=\% 2$ Fnetahtml $\% 2$ FPTO $\% 2$ Fsearch bool.html\& $\mathrm{r}=1 \& \mathrm{f}=\mathrm{G} \& \mathrm{l}=50 \& \mathrm{co} 1=\mathrm{AND} \& \mathrm{~d}=\mathrm{PTXT} \& \mathrm{~s} 1=10634101 \& \mathrm{OS}=10634101 \& \mathrm{R}$ $\mathrm{S}=10634101$

8. United States Patent no. 10,480,432, Application No. 15/507,451, http://patft.uspto.gov/netacgi/nph-

Parser?Sect $1=$ PTO $2 \&$ Sect $2=$ HITOFF $\& p=1 \& u=\% 2$ Fnetahtml $\% 2$ FPTO $\% 2$ Fsearchbool.html\&r=1\&f=G\&l=50\&col=AND\&d=PTXT\&s $1=10480432 \& O S=10480432 \& \mathrm{R}$ $\mathrm{S}=10480432$

9. United States Patent no. 10,288,014, Application No. 15/721,587, http://patft.uspto.gov/netacgi/nph-

Parser?Sect $1=$ PTO $2 \&$ Sect $2=$ HITOFF $\& p=1 \& u=\% 2$ Fnetahtml $\% 2$ FPTO $\% 2$ Fsearch bool.html\&r=1\&f=G\&l=50\&co1=AND\&d=PTXT\&s $1=10288014 \& O S=10288014 \& \mathrm{R}$ $\mathrm{S}=10288014$

10. United States Patent no. 10,215,086, Application No. 15/325,578, http://patft.uspto.gov/netacgi/nph-

Parser?Sect $1=$ PTO $2 \&$ Sect $2=$ HITOFF $\& p=1 \& u=\% 2$ Fnetahtml $\% 2 F P T O \% 2 F$ search bool.html\& $\mathrm{r}=1 \& \mathrm{f}=\mathrm{G} \& \mathrm{l}=50 \& \mathrm{co} 1=\mathrm{AND} \& \mathrm{~d}=\mathrm{PTXT} \& \mathrm{~s} 1=10215086 \& \mathrm{OS}=10215086 \& \mathrm{R}$ $\mathrm{S}=10215086$

11. United States Patent no. 9,903,319, Application No. 15/003,245, http://patft.uspto.gov/netacgi/nph-Parser?

12. United States Patent no. 9,574,526, Application No. 14/763,933, http://patft.uspto.gov/netacgi/nph-Parser

13. M. Meerovich, L. Shragina, Technology of creative thinking, 298-316 (2016)

14. I. Ivanov, G. Persiyanova, Collection of articles of the 8th international scientificpractical conference "Interagromash -2015", 592-596 (2015)

15. I. Ivanov, Patent RF. №2734087 (2020) 